\title{
The Determination of Distance at Sea by Vertical Angle
}

\author{
V. L. Bosazza
}

THE very interesting short note by Cotter in the July issue of the Journal is of importance in the history of survey methods used in charting the harbours of East Africa and the delta of the Zambezi. In my researches into the achievements of the Zambezi Expedition of $185^{8}$, I finally found in Francis Owen's book that the vertical angle method had been used in 1820 and also in the voyages of Leven and Barracouta from 1821 to 1823.1 In I 8.20 Captain W. F. M. Owen in collaboration with the staff at Woolwich calibrated rockets in order to measure distances at sea. The experiments are described in the following words (Vol. I, page 2):

'Whilst at Woolwich various experiments were made upon the flight of rockets, which had been recommended by Captain Owen to the Admiralty as a ready and simple method of measuring the difference between two places not very distant.'

The following details are given in a recent reprint of the book:

\begin{tabular}{c|c|c}
\hline $\begin{array}{c}\text { Weight of rocket } \\
\text { in pounds }\end{array}$ & Vertical height in feet & Visibility \\
\hline 32 & 6000 & 55 geographical miles \\
12 & 3500 (interpolated) & \\
0.5 & 2400 \\
0.25 & 1500 & \\
\hline
\end{tabular}

Between the $32 \mathrm{lb}$. and the $0.5 \mathrm{lb}$. rockets the heights attained were said to be proportional, and a plot of the results indicates that the curve is becoming asymptotic at about $12 \mathrm{lb}$. and $6000 \mathrm{ft}$. The rockets were also used at night and according to the account by Forbes during the survey of the Cape Verde Islands the parachute light hung suspended for upwards of 6 minutes (Owen, op. cit., p. 26).

Examining the charts of False Bay and Table Bay by Lieutenant Vidal for example, it is evident that vertical angles were used not only for the determination of the distance between Simon's Bay and Gordon's Bay, but for the offshore surveys as well. Table Mountain, Devil's Peak, Lion's Head and many other features were surveyed and the elevation of the highest points determined. It is where these heights are in serious error that errors can be found, as in the location of Bellow's Rock at Cape Point, the Anvil Rock and Whittle Rock, where the errors in position were due to an inaccurate determination of the height of Cape Peak.

The officers of Leven and Barracouta carried out the survey of the Bay of Lourenço Marques in 1822 and used masthead heights for the whole survey. 
This chart is not as accurate as those of Cape Town or False Bay where a base control between Simon's Bay and Gordon's Bay by rocket was the basis for fixing the positions of land features. In addition the distance between Devil's Peak and a Cape peak was determined by astronomical methods as these lie almost on the same meridian and are intervisible.

Similar surveys of a high standard of accuracy were made of the Bays of Conducia, Mokambo and Mombas (Mombassa) during the same voyage. In 1858 Francis Skead and members of the Zambezi Expedition used masthead determinations to survey the Zambezi Delta and River to above Tete. The earlier surveys by three officers of the famous Canoe Expedition in the Lower Zambezi are not known to me.

I think Raper described the method in his books on navigation, but I have not been able to find a copy; the second edition was published in 1842 . I have a photostat copy of Becher's work published in I 854 and find it very useful as it gives tabulations for heights of the main truck of $30,35,40$ and $50 \mathrm{ft}$., common heights for modern yachts. The distances are given in miles and yards; the tables are actually fuller than this, being in intervals of $5 \mathrm{ft}$. and then $10 \mathrm{ft}$., up to $208 \mathrm{ft}$.

\title{
REFEREN CES
}

1 Owen, W. F. M. (1833). Narrative of Voyages to Explore the Shores of Africa, Arabia and Madagascar performed in H.M. Ships Leven and Barracouta. London, Bentley, Vol. I, p. $24^{2}$ and Vol. II, P. 420.

2 Becher, A. B. (1854). Tables of Masthead Angles for five feet intervals from 30 to 208 feet and varying distances from a cable's length to four miles. London, J. D. Potter.

3 Raper, H. (1842). The Practice of Navigation and Nautical Astronomy, 2nd edition.

4 Belcher, E. (1835). A Treatise on Navigation, containing an outline of the duties of the Naval Surveyor with cases applied to naval evolutions and miscellaneous rules and tables useful to the seaman or traveller. London, Pelham Richardson.

\section{Collisions and Groundings}

\author{
A. G. Dunne \\ (S. S. Stevenson and Partners Ltd.)
}

THE number of collisions and groundings and the contact damage suffered by merchant ships every year is considerable, the averages for the years 1965-70 inclusive showing that some i 5 per cent of the world's shipping over 500 g.r.t. has been involved annually in such accidents. United Kingdom shipping is no exception, and collisions and groundings alone as reported in Lloyd's Daily Lists during the first four months of 197 I show that ships from some 27 companies were involved, some with more than one incident reported although none had more than three. Collisions, groundings and contact damage are likely to occur if a ship's captain and his bridge watch keeping officers do not have immediately available in a simple form, complete information about their ship and her navigational equipment, and detailed information covering the essential tasks performed on the bridge. Unfortunately however, in a great number of ships, most of this information is not provided in an easily usable form and, as a result, 